\title{
NONLINEAR RELATIVE STABILITY ANALYSIS OF SOME NIGERIAN GEOLOGICAL FORMATIONS AS RADIOACTIVE WASTES REPOSITORY
}

\author{
T. A. Fashanu 1,*, K. O. Orolu' ${ }^{2}$, A. S. Adeshina ${ }^{3}$, M. A. Ogundero ${ }^{4}$ and \\ O. Ibidapo-Obe ${ }^{5}$

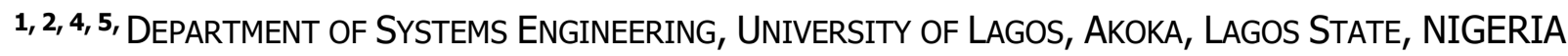

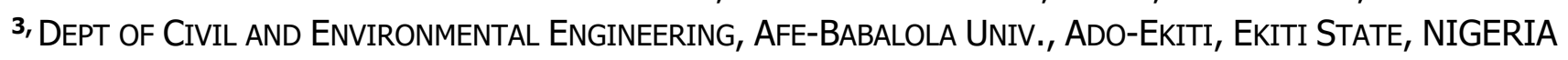 \\ Email addresses: ${ }^{1}$ tfashanu@unilag.edu.ng, ${ }^{2}$ korolu@unilag.edu.ng, ${ }^{3}$ adebanjo.as@abuad.edu.ng, \\ ${ }^{4}$ mogundero@unilag.edu.ng, ${ }^{5}$ oye-ibidapo-obe@unilag.edu.ng
}

\begin{abstract}
This work determines the relative capabilities of some geological formations in Nigeria as radioactive wastes repository. Reaction term of the advection-diffusion-reaction transport in porous media was reworked to address nonlinear radioactive decay and sorption. Lyapunov's indirect method identified three critical points. A stable attractor at the origin, flanked by two symetric saddles. Phase Potraits show that Caesium and Strontium are well stabilized in sandstone, consolidated clay and limestone. In shale, the focus at the origin indicates weak stability for the two radionuclides. However, for Plutonium, the origin is consisitently a weak node. Hence, its dynamics/disappearance rate is very slow. At half-lifes, breakthrough curves in $200 \mathrm{~cm}$ radius of host soils show that Strontium and Caesium are best contained in sandstone and consolidated clay. However, they deeply infilterate limestone. Similarly, a fifth of Plutonium's reposed concentration completely infiltrated the simulation aperture. Hence, Plutonium should not be reposed in natural formations.
\end{abstract}

Keywords: radionuclides activity, infiltration rate, relative stability, fixed points, geological formation

\section{INTRODUCTION}

In Nigeria, availability of affordable, clean and regular electricity supply has been identified as fundamental prerequisites for industrialization. Presently, there is an estimated shortfall of 8.52 Mega Watts per day in available electric energy in the country [1]. To close this gap, nuclear power stations have been recommended. This would be consistent with the source of energy that supported early development in parts of Europe and United States. However, due to geopolitics and inadequate geo-technical skills [2], handling of radioactive wastes is a primary concern in Nigeria and some other countries.

In practise, depending on the chemical potential, radioactive wastes are categorized as low level, high level or transuranic [3]. They derive from spent nuclear fuels, medical wastes, and other sources. To safely dispose high level wastes, deep geological repositories are designed to host waste canisters cased in engineered barrier systems (EBS), [4]. The objective is to separate radionuclides from the environment until they decay below a safe threshold. In the event of accidental release, the host soil should delay ions migration to the surrounding for a safe period, [5]. Otherwise, radionuclides migrate to contaminate neighboring soils and aquifers.

Standard practice use analysis of mass/charge ratio to determine the technical process for handling radionuclides. It is a study of decay property to determine relative toxicity of radionuclides. For, safe handling, wastes are kept in special canisters and buried in appropriate geological sites. Due to exothermic nature of radionuclides decay, corrosion, and other stress agents; buried canisters may leak 
and release content into the environment. In the absence of a stable barricading host soil or rock, the ions will pollute neighboring environment. Otherwise, the radionuclides is retained and attenuated in the immediate host soil. This outcome depends on the dynamics of radionuclide in host soil. Stable dynamics ensures adequate rentention and decay to admissible level before reaching freshwater aquifer. Hence, this work examines the relative stability of the dynamics of some radionuclides in some geological soils in Nigeria.

\section{BRIEF DESCRIPTION OF NIGERIAN LITHOLOGICAL SYSTEM}

Summary of the structural layout of Nigerian soils and aquifers indicates that about a third of the land mass is underlain with igneous granitic and metamorphic rocks. Such regions are called the Basement Complex. They are mostly present in the South and Mid-Western parts and have patches throughout the country. Within this formation, small quatities of water is stored in fractures, or weathered mantles overlaying impervious base.

With few exceptions, sedimentary basins of varied geophysical properties constitute the balance of Nigeria's lithological system. For example, the upper plains of river Benue, towards the boundary with Cameroon is covered with continental sediments. It started with quaternary alluvium at the banks of the Benue, and progressively graduates to a sequence of sandstone, limestone and shale. By the volcanic plateau of the lower Benue, the sediments consist of marine shale, silty shale, and inter- bedded sandstones that are invaded by dolerites, basalt plugs and laterites.

The sediments of Idah Ankpa basin is an aggregate of fine to coarse-grained sandstone, carbonaceous shale, oolitic limestone, pervious ironstone pebbles, silts and clayey grits. It extends from the confluence of the Niger at Lokoja through the Federal capital territory to North Central and North Western Nigeria. Sediments of the Sokoto basin and the well-known Gwandu formation are the prominent lithology of Northwestern Nigeria. They are alternating sequence of sand, clay, laterite, clayey sandstone, occasional limestone and gypsum. Distributed all over North Central and North Eastern Nigeria are massive clay, loosely cemented silty sand and bands of ironstones that are laid on an uneven surface of basaltic basement. Finally, the Chad Basin complements the lithological structure with intra formational clay, silts as well as lenses of sandstone and gravel occurring at various depths.

\section{GEOTECHNICAL PRACTICE FOR SPENT FUEL REPOSITORY}

According to [6], unresolved issues with final disposal of radioactive wastes limit the use of nuclear fuels for power generation. In practise, low permeability rocks and soils are used to store canisters of spent fuels in open cavity of rocks or at predetermined depths in soils. For open cavity waste deposits, safety factors include; retention time, irretrievability of the deposits and ability of rock mass to absorb the heat generated by radioactive decay. Despite these precautions, spent fuels are known to induce and permeate fractures in rocks to infilterate freshwater aquifer. Similarly, waste creeping, especially when cavities are opened to retrieve canisters limits the use of salt beds as repositories [7].

It is rare that a carefully engineered barrier system would fail. However, there exists a remote possibility of radionuclides moving beyond the barrier system. Thus, to guarantee safe disposal, deep repository operations technically consider physical and chemical interactions between the host soil and reposed radio active waste. In this regard, [6] strongly suggested that the natural ability of the host soil to resist the movement radionuclides should also be a fundamental requirement for siting repository. However, radionuclide retention of the host soil depends on the relative stability of physical and chemical interactions between the radionuclide and soil. Perharps, due to the recommendations of [6], modern geotechnical disposal practices now consider multiple barrier layers around buried canisters. Despite this precaution, the possibility of leakage cannot be completely excluded. Therefore, this work present an analysis of the relative capabilities of some geological formations in Nigeria to host radioactive wastes.

\section{DYNAMICS OF SPENT RADIONUCLIDE TRANSPORT IN SOILS AND AQUIFERS}

The principle of mass and momentum transport determines contaminants' fate in porous media. For radionuclides; physico-chemical phenomena, soil and radioactive decay properties of the reposed waste complement the transport process. To establish the effects of these terms, [8] designed and implemented an experimental framework that used electro-kinetic analysis to determine the the contributions of 
transport mechanisms and soil properties to the stability of reposed radionuclides in geological systems. The examined soil properties include; porosity, conductivity and bulk density. In addition, [9] studied the influence of hydrologic paramters such as dispersity and volumetric water content on the dynamics of soil-radionuclide systems, and [10] analysed the roles of radionuclide properties such as half-life, radioactive decay constant and adsorption coefficient.

Characterizing the retention of contaminants in soils and aquifers with adsorption and solid/liquid distribution coefficients assume steady state groundwater flow system. However, in deep geological repository with inconsistent transport condition, chemical disequilibrium may exist. Therefore, [5] proposed a reactive transport regime to complement transport dynamics. Thus, net transport is controlled by the geochemical reaction term. This may introduce certain nonlinearity into the system. Such model was extended by [11] to examine the sustainability of waste water re-injection process into spent hydrocarbon aquifers.

Standard procedures such as analytical, semianalytical or numerical representations of contaminant transport in porous media, are deficient in ability to handle system's non-linearities. Thus, this work uses basic operational methods of engineering analysis, the indirect method of Lyapunov for nonlinear stability analysis and Phase Plane approach in the manner presented by [12] to study the dynamics of soil /radionuclide interaction system. This provides a basis for the determination and synthesis of suitable host soil for reposing spent nuclear fuels or allied wastes.

\section{STABILITY ANALYSIS OF SOIL- RADIONUCLIDE INTERACTIVE SYSTEM}

The advection-diffusion-reaction equation models contaminant transport in porous media. For radionuclides, a nonlinear reaction term of the form $\gamma C\left(1-C^{2}\right)$ is considered to account for logarithmic decay and adsorption processes. This is consistent with the method used by [13]. Thus, the reworked advection-diffusion-nonlinear reaction equation is given as;

$$
\frac{\partial C}{\partial t}=a \frac{\partial C}{\partial x}+D \frac{\partial^{2} C}{\partial x^{2}}+\gamma C\left(1-C^{2}\right)
$$

With $C(0, t)=C_{0} ; \quad C(x, 0)=C(1, t)=0$ where, $C$ is the concentration (or activity) of the radionuclide in soil. $a$ is the coefficient of advection, $D$ is the coefficient of diffusion and $\gamma$ is the rate constant of combined geochemical reaction and radionuclide decay. These parameters represent hydrological properties of host soil and physicochemical properties of radionuclides.

For nonlinear stability analysis, the travelling wave coordinate $z=x-v t$ is introduced to solve equation (1). In this case, $z$ is the depth that the contaminant will penetrate after a period of time $t, x$ is the location of buried canister, $v$ is the constant speed at which radionuclide infilterate the soil, [14]. Differentiating the travelling wave coordinate with respect to time and rearranging gives,

$$
d t=-\frac{1}{v} d z ;
$$

Equation (3) is used to convert equation (1) to second order ordinary differential equation of the form;

$$
\frac{d^{2} C}{d z^{2}}+\left(\frac{a+v}{D}\right) \frac{d C}{d z}+\frac{\gamma}{D} C\left(1-C^{2}\right)=0
$$

In compact form. Equation (4) is expressed as;

$$
\begin{aligned}
& \text { where }(')=\frac{d}{d z} \\
& C^{\prime \prime}+\left(\frac{a+v}{D}\right) C^{\prime}+\frac{\gamma}{D} C\left(1-C^{2}\right)=0
\end{aligned}
$$

Setting $p=C$ and $q=C^{\prime}$, then;

$$
\begin{gathered}
p^{\prime}=q \\
q^{\prime}=\frac{\gamma}{D} p\left(p^{2}-1\right)-\left(\frac{a+v}{D}\right) q
\end{gathered}
$$

\section{ANALYSIS OF THE DYNAMICS OF SOIL- RADIONUCLIDE INTERACTION}

For stability analysis of the soil-radionuclide system, three fixed points are easily indentified on the phase plane of $(p, q)$ as described by equation (6). Coordinates of the fixed points are; $\left(p_{1}, q_{1}\right)=(0,0)$; $\left(p_{2}, q_{2}\right)=(-1,0)$ and $\left(p_{3}, q_{3}\right)=(1,0)$.

By the indirect method of Lyapunov, the Jacobian of the system in Equation (6) is obtained as,

$$
J(p, q)=\left(\begin{array}{cc}
0 & 1 \\
\frac{\gamma}{D}\left(3 p^{2}-1\right) & -\left(\frac{a+v}{D}\right)
\end{array}\right)
$$

The Eigenvalues are determined by; 


$$
\operatorname{det}(\lambda I-J)=0
$$

This implies;

$$
\begin{aligned}
& \left|\begin{array}{cc}
\lambda & 1 \\
\frac{\gamma}{D}\left(3 p^{2}-1\right) & \lambda+\left(\frac{a+v}{D}\right)
\end{array}\right|=0 \\
& \text { i.e. } \lambda^{2}+\lambda\left(\frac{a+v}{D}\right)-\frac{\gamma}{D}\left(3 p^{2}-1\right)=0
\end{aligned}
$$

These characteristic values are,

$$
\lambda_{1}, \lambda_{2}=\frac{-\left(\frac{a+v}{D}\right) \pm \sqrt{\left(\frac{a+v}{D}\right)^{2}+4 \frac{\gamma}{D}\left(3 p^{2}-1\right)}}{2}
$$

For the purpose of relative stability analysis, the characteristics of the critical points are considered one after the other.

Case $1,\left(p_{1}, q_{1}\right)=(0,0)$; the corresponding Eigenvalues are;

$$
\begin{aligned}
& \lambda_{1}=\frac{-\left(\frac{a+v}{D}\right)+\sqrt{\left(\frac{a+v}{D}\right)^{2}-4 \frac{\gamma}{D}}}{2} \\
& \lambda_{2}=\frac{-\left(\frac{a+v}{D}\right)-\sqrt{\left(\frac{a+v}{D}\right)^{2}-4 \frac{\gamma}{D}}}{2}
\end{aligned}
$$

This presents two possibilities;

If $\left(\frac{a+v}{D}\right)^{2}>4 \frac{\gamma}{D}, \lambda_{1}, \lambda_{2}$ are real and negative.

The critical point is a node. Hence, the dynamics of soil-radionuclide system is asymptotically stable at this fixed point.

On the other hand, if $\left(\frac{a+v}{D}\right)^{2}<4 \frac{\gamma}{D}, \lambda_{1}, \lambda_{2}$ are complex conjugates. The critical point is a spiral. The real part is nonzero and negative, therefore the system is stable. In both cases, the critical point at the origin i.e. $\left(p_{1}, q_{1}\right)=(0,0)$, is stable by Lyapunov indirect method.

Case 2, $\left(p_{2}, q_{2}\right)=(-1,0)$; the corresponding Eigenvalues are;

$$
\lambda_{1}=\frac{-\left(\frac{a+v}{D}\right)+\sqrt{\left(\frac{a+v}{D}\right)^{2}+8 \frac{\gamma}{D}}}{2}
$$

$$
\lambda_{2}=\frac{-\left(\frac{a+v}{D}\right)-\sqrt{\left(\frac{a+v}{D}\right)^{2}+8 \frac{\gamma}{D}}}{2}
$$

In this case, the eigenvalues are distinct, real and opposite in signs. $\lambda_{1}>0$, and $\lambda_{2}<0$. Therefore, the critical point is an unstable saddle.

Case 3, $\left(p_{3}, q_{3}\right)=(1,0)$; the corresponding Eigenvalues are;

$$
\begin{aligned}
& \lambda_{1}=\frac{-\left(\frac{a+v}{D}\right)+\sqrt{\left(\frac{a+v}{D}\right)^{2}+8 \frac{\gamma}{D}}}{2} \\
& \lambda_{2}=\frac{-\left(\frac{a+v}{D}\right)-\sqrt{\left(\frac{a+v}{D}\right)^{2}+8 \frac{\gamma}{D}}}{2}
\end{aligned}
$$

Identical to Case 2; the eigenvalues are distinct, real and opposite signs. The fixed point is unstable saddle.

\section{RESULTS AND DISCUSSION}

The stable fixed point at the origin as obtained from equations (6) and (13) physically represents the final state of decomposition for any initial concentration and decay rate of radionuclide. However, this node is symmetrically bounded by two saddle points; $\left(p_{2}, q_{2}\right)=(-1,0)$, to the left and $\left(p_{3}, q_{3}\right)=(1,0)$ on the right. Apparently, the saddle point to the left of origin is an exterior fixed point, probably representing situations in mines.

However, the saddle to the right of the origin i.e. $\left(p_{3}, q_{3}\right)=(1,0)$ represents the initial state of soilradionuclide dynamics. This is the situation at the time when a buried canister contataining radioactive waste fails and its content released into the host soil. Subsequently, the waste decay from the saddle to trace the attractor at the origin. Combining the outcome of Lypunov indirect method with the vector field approach [15], the resultant Phase Portrait of the system is presented in Figure 1. Clearly, according to the index theory of dynamical systems analysis [16], the soil-radionuclide dynamics is not conserved. Thus, the Phase Potrait in Figure 1, and the subsequent ones in Figures 2 to 5 are consistent with the physics of radionuclide transport in porous media. 
Trajectories of specific radionuclides in different host soils are subsets of Figure 1. Radionuclides of interest in this study are Strontium (Sr), Caesium (Cs) and Plutonium (Pu). Some identified possible host soils in Nigeria are selected for analysis. These include, consolidated clay, limestone and shale. To examine the relative stability of each of these soil-radionuclide systems, the Eigenvalues of each combination are evaluated by equation (15) with parameters obtained from Table 1. These characteristic values are shown in Table 2. They are used to construct Phase Potraits illustrating the relative dynamics of the binary systems. The Potraits are presented in Figures 2 to 5.

These Figures present the dynamics of Strontium, Caesium and Plutonium in simulated host soils. In consolidated clay, given a normalized initial concentration, the three radionuclides trace the attractor at the origin. Apparently, Strontium is the most stable in consolidated clay, followed by Caesium. The Phase Portraits in Figure 2 give the comparative dynamics of the radioactive wastes in consolidated clay. Due to its relatively low conductivity and diffusion coefficient, the radionuclides are strongly attracted to the stable origin in consolidated clay. These parameters determined the Eigenvalues as real negative numbers in consolidated clay. Hence, the radionuclides are strongly confined to the neighbourhood of the leaking canister in consolidated clay.

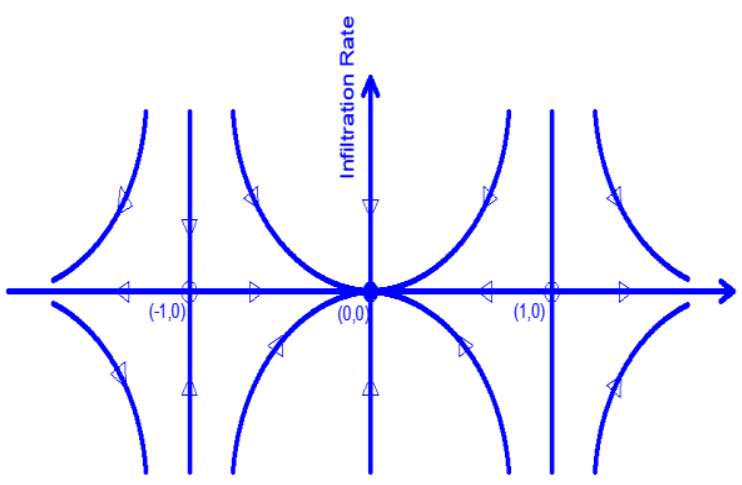

Normalized Concentration

Figure 1: Phase Potrait of Radionuclides Transport in Porous Media

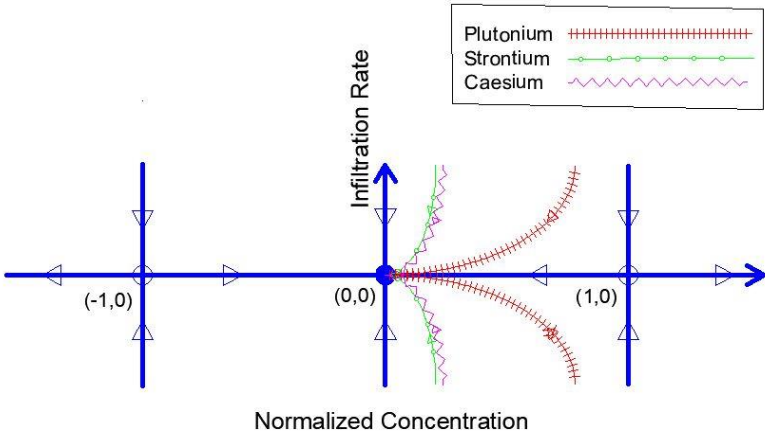

Figure 2: Relative Infiltration Trajectories of Some Radionuclides in Consolidated Clay

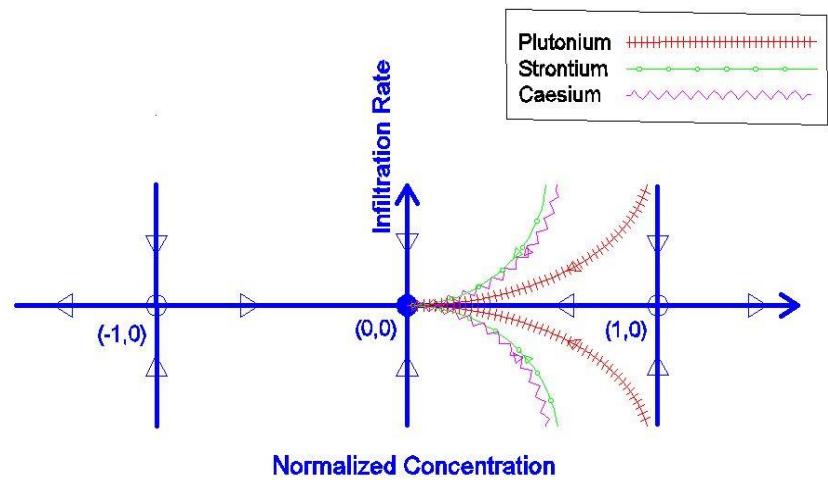

Figure 3: Relative Infiltration Trajectories of Some Radionuclides in Limestone

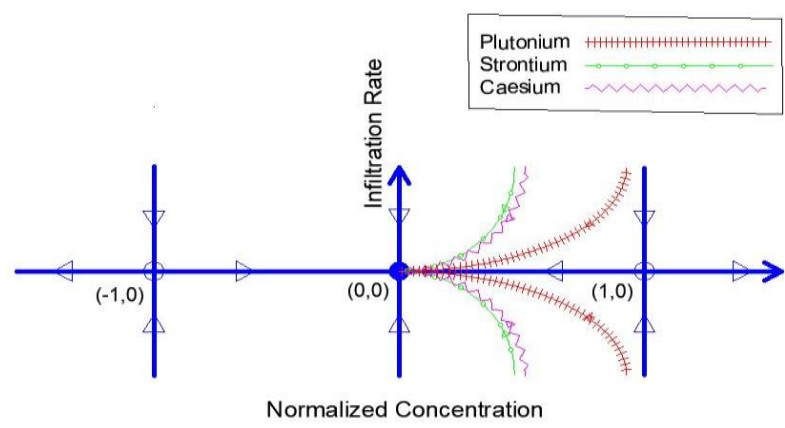

Figure 4: Relative Infiltration Trajectories of Some Radionuclides in Sandstone

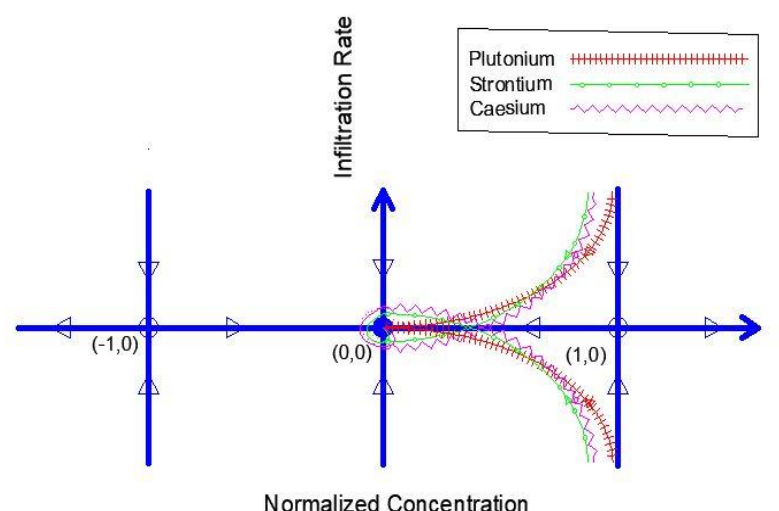

Figure 5: Relative Infiltration Trajectories of Some Radionuclides in Shale 
Nonlinear Relative Stability Analysis of Some Nigerian Geological Formations as Radioactive Wastes Repository, T. A. Fashanu. et. al

Table 1 :Normalized Average Properties of Radionuclides in selected Soil Types

\begin{tabular}{lllllll}
\hline \multirow{2}{*}{ Soil } & \multicolumn{2}{l}{ Darcy Velocity a $(\mathrm{cm} / \mathrm{yr})$} & \multicolumn{3}{l}{ Diffusion Coefficient $D\left(\mathrm{~cm}^{2} / \mathrm{yr}\right)$} \\
\cline { 2 - 6 } & Strontium & Caesium & Plutonium & Strontium & Caesium & Plutonium \\
\hline Consolidated clay & 0.001037736 & 0.001110559 & 0.000022568 & 0.0594532440 & 0.0636251414 & 0.0012929192 \\
Limestone & 0.093888219 & 0.101016656 & 0.001900228 & 0.0087494424 & 0.0094137168 & 0.0001770819 \\
Shale & 0.000015606 & 0.000016734 & 0.000000330 & 7.4410800336 & 7.9789864320 & 0.1574923608 \\
Sandstone & 0.000426315 & 0.000458693 & 0.000008626 & 0.1298542104 & 0.1397164637 & 0.0026273745 \\
\hline Average & & & & & & \\
$\begin{array}{l}\text { Radioactive } \\
\text { Decay constants Y }\end{array}$ & 0.024046042 & 0.022217711 & 0.000028855 & & & \\
(yr-1) for Three & & & & & & \\
Isotopes & & & & & & \\
Compiled from: $[17-19]$ & & & & & & \\
\end{tabular}

Table 2 Eigenvalues of Soil-Radionuclide Systems for the Fixed Point at $(p, q)=(1,0)$

\begin{tabular}{|c|c|c|c|c|c|c|}
\hline \multirow[t]{2}{*}{ Soil Type } & \multicolumn{3}{|c|}{$\lambda_{1}$} & \multicolumn{3}{|c|}{$\lambda_{2}$} \\
\hline & Strontium & Caesium & Plutonium & Strontium & Caesium & Plutonium \\
\hline $\begin{array}{l}\text { Consolidate } \\
\text { d clay }\end{array}$ & -0.259068 & -0.239025 & -0.000289 & -3.12237515 & -2.92184083 & -154.70586949 \\
\hline Limestone & -0.16444583 & -0.14830566 & -0.00028584 & -33.42491952 & -31.82808198 & -1140.15144995 \\
\hline Shale & $\begin{array}{l}-0.01343996 \\
+0.07926171 i\end{array}$ & $\begin{array}{l}-0.01253397 \\
+0.073565995 i\end{array}$ & -0.00028862 & $\begin{array}{l}-0.01343996 \\
0.07926171 i\end{array}$ & $\begin{array}{l}-0.01253397 \\
0.073565996 i\end{array}$ & - $\quad-1.26961634$ \\
\hline Sandstone & -0.29716045 & -0.273992685 & -0.00028854 & -1.24631137 & -1.16076087 & -76.1246122 \\
\hline
\end{tabular}

Computed from: [4], [17] and [18]

Since the Eigenvalues are equally real and negative in Limestone and Sandstone formations, trajectories of the radionuclides in these soils are similar to their trajectories in consolidated clay. However, as determined by the relative magnitudes of the negative Eigenvalues, the gradient of the vector field is not as steep in Limestone and Sandstone formations when compared with Consolidated clay. Hence, the trajectories approached the stable origin at slower speeds. Meanwhile, because the Eigenvalues of of the dynamics of Caesium and Strontium are close in Sandstone, their trajectories nearly converge in the formation. These Portraits are shown in Figures 3 and 4.

In Shale, the chataeristic values of the origin are complex conjugates with negative real part for Caesium and Strontium, but real and negative for Plutonium. Hence, the origin is a stable focus for Caesium and Strontium but a stable node for Plutonium. However, the magnitude of the negative real part of the Eigenvalues of Caesium and Strontium are higher than the negative Eigenvalues of Plutonium in Shale. Hence, although Plutonium is more stable in Shale compared with Caesium and Strontium, their trajectories spiraled faster to the origin than Plutonium's trajectory. The descriptive Phase Portraits of the radionuclides in Shale is shown in Figure 5. The trajectories in Figures 2 to 5 are consistent with the comprehensive experimental results and physicochemical analyses of [20].

For the breakthrough curves of radionuclides in selected formations, direct simulation of relative infiltration profiles in each medium gives the following results. In consolidated clay, (Figure 6); concentrations of Strontium and Caesium peaked at about $50 \%$ of its value at the outer wall of the engineered barrier system. An accumulation layer of about $22 \mathrm{~cm}$ is developed in consolidated clay. This layer starts from the wall of the container system. Beyond this layer, the concentration decay asymptotically with depth. Ultimately, at 80centimeters into consolidated clay formation, the concentration of Caesium and Strontium reduced to zero.

In sandstone, (Figure 7); the profiles of Caesium and Strontium is similar to what obtained in consolidated clay. However, the sorption dominant zone is thicker, $34 \mathrm{~cm}$ in this case. Similar to what was obtained in consolidated clay, Caesium and Strontium disappeared in sandstone at about $80 \mathrm{~cm}$ away from the canister. However, as established from the Phase Potraits, their rate of disappearance with depth is faster in clay than sandstone. 


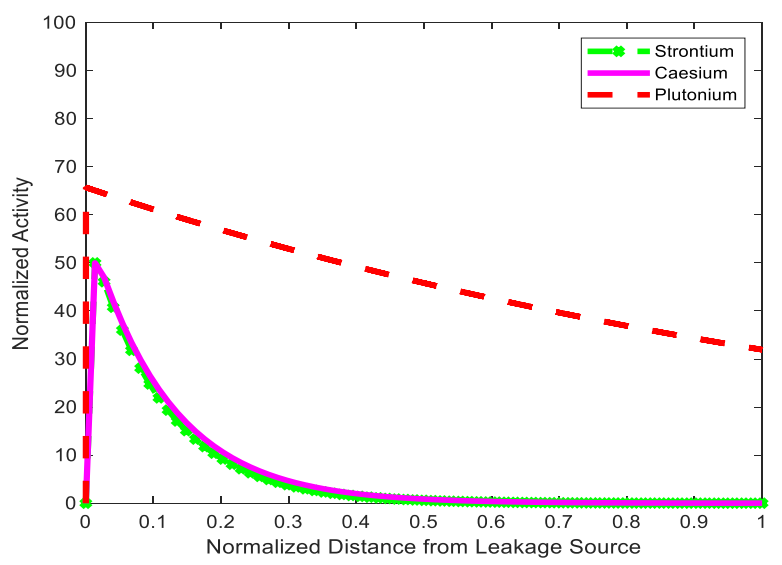

Figure 6: Radionuclides in Consolidated clay

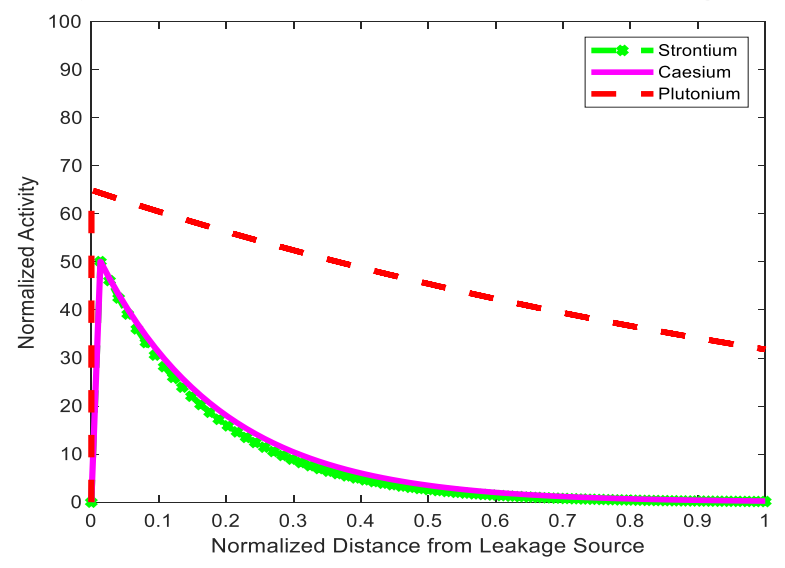

Figure 8: Radionuclides in Limestone

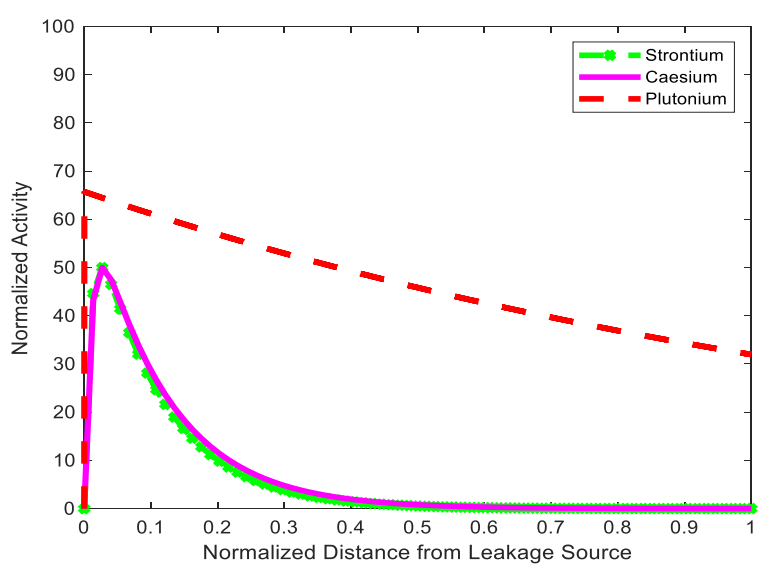

Figure 7: Radionuclides in Sandstone

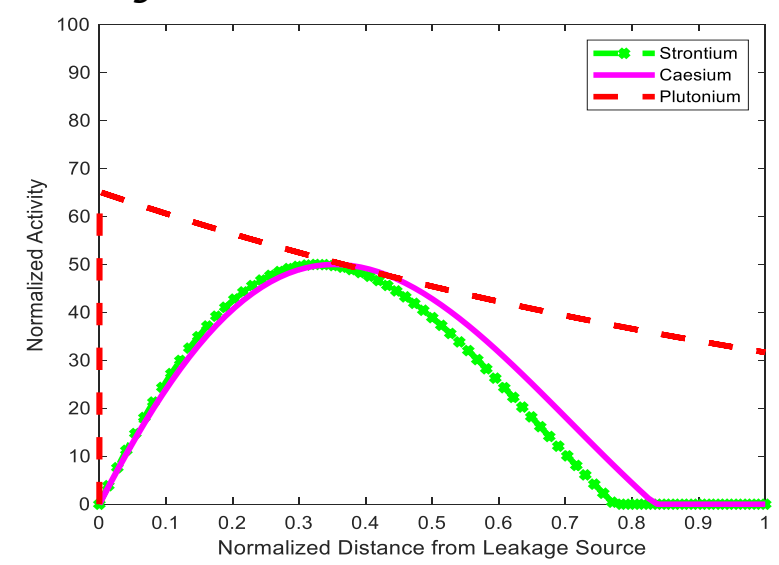

Figure 9: Radionuclides in Shale

For Caesium and Strontium in limestone, the thickness of the layer is less than $14 \mathrm{~cm}$ with Strontium penetrating further than Ceasium. This trend fully agrred with the field observations and explanations of [21] However, due to the presence of macro fissures that provide advection pathways for relatively small radionuclides, Strontium and Ceasium penetrated up to $106 \mathrm{~cm}$ of limestone before they disappeared. Compared with Consolidated Clay and Sandstone, this indicates a lower capacity of Limestone to host Caesium and Strontium.

The dynamics of Strontium and Caesium is different in Shale compared with other formations. According to the breakthrough curves in Figure 9, their concentration penetrated almost $80 \%$ of the simulation aperture. In addition, the accumulation layer's concentration peaked at about $52 \%$ in Shale. Hence, of the four formations, Shale has the least capacity to host Caesium and Strontium.

Unlike Caesium and Strontium, Plutonium concentration is much higher at the EBS's wall. This is due to its much longer half-life compared with

Caesium and Strontium. Plutonium infiltrated the entire $200 \mathrm{~cm}$ simulated soil thickness. Meanwhile, it's breakthrough curves are consistent in the four formations considered. Its activity at the end of the simulation aperture in the soils is about $32 \%$.

\section{CONCLUSION}

This work studied the nonlinear dynamics of soilradionuclide interaction in the absence of pore water and electrolytes to determine the relative capabilities of some geological formations in Nigeria to host radionuclide wastes. A Lyapunov indirect method for stability analysis and Phase Portraits of the dynamics of Caesium, Strontium and Plutonium in Consolidated Clay, Sandstone and Limestone showed that the origin is an asymptotically stable attractor for all trajectories that originated within physically realistic normalized concentrations of the radionuclides in host soils. However, shale is an exception, where trajectories of Caesium and Strontium spiralled to the origin. It was also established that except in Shale, 
Caesium and Strontium are more stable than Plutonium in all formations.

Confirmatory analyses of half-life breakthrough curves of radionuclides on a $200 \mathrm{~cm}$ simulation aperture of the selected formations show that sandstone and consolidated clay have very good capacities to contain Caesium and Strontium leakage. However, Limestone demonstrated poorer ability to store and disintegrate radionuclides prior to infiltration. Hence, compared with consolidated clay and sandstone, limestone is not a good host for Caesium and Strontium. Meanwhile, Shale lacks the capacity to contain Caesium and Strontium.

Finally, though Plutonium is adjudged stable at the origin in the four formations; however, its trajectory is very slow. Hence, relatively high and harmful font of Plutonium infiltrates and pollute host soil. Consequently, except with detailed precautions, none of the formations examined should be considered for Plutonium repository.

Summarily, this work developed a nonlinear analytical framework for selecting possible Nigerian geological formations to safely host engineered barrier systems of radioactive wastes. The framework uses indirect method of Lyapunov stability analysis to characterize the dynamics of soil-radionuclide interaction and determine radioactive wastes handling abilities of some Nigerian lithological systems. Clearly, combined nonlinear stability analysis and contaminant's beakthrough curves in porous media are necessary tools to safely select radioactive waste repository.

\section{REFERENCES}

[1] USAID, "NIGERIA: POWER AFRICA FACT SHEET," 2019. [Online]. Available: https://www.usaid.gov/powerafrica/nigeria.

[2] F. Berkhout, Radioactive Waste: Politics and Technology, 1991.

[3] M. I. Ojovan, R. A. Robbins and M. Garamszeghy, "Advances in conditioning of low-and intermediate-level nuclear waste," Scientific Basis for Nuclear Waste Management XLI, vol. 13, no. 19, pp. 983-990, 2017.

[4] A. Malekifarsani and M. A. Skachek, "Effect of precipitation, sorption and stable of isotope on maximum release rates of radionuclides from engineered barrier system (EBS) in deep repository," Journal of Environmental
Radioactivity, vol. 100 , no. 10 , pp. $807-814$, 2008.

[5] À. Piqué, A. David, G. Fidel, M. Jorge, D. Lara and B. Sten, "Conceptual and numerical modeling of radionuclide transport and retention in nearsurface systems." Ambio 42, no. 4 (): .," AMBIO, vol. 42, no. 4, pp. 476-487, 2013.

[6] J. A. Cherry, W. M. Alley and B. L. Parker, "Geologic Disposal of Spent Nuclear Fuel. The Bridge on Emerging Issues in Earth Resources Engineering," vol. 44, no. 1, pp. 51-59, 2014.

[7] D. G. Brookins, Geochemical aspects of radioactive waste disposal, Springer Science \& Business Media, 2012.

[8] S. Pamukcu and J. K. Wittle, "Electrokinetic removal of selected heavy metals from soil," Environmental Progress \& Sustainable Energy, vol. 11, no. 3, pp. 241-250., 1992.

[9] H. O. Chang, Hazardous And Radioactive Waste Treatment Technologies Handbook, CRC press, 2001.

[10] R. Saint-Fort, Understanding Sorption Behavior and Properties of Radionuclides in the Environment, IntechOpen, 2018, pp. 121-150.

[11] O. Ibidapo, T. A. Fashanu, I. O. Peter, A. O. Tope and A. E. Kingsley, "Produced water re-injection in a non-fresh water aquifer with geochemical reaction, hydrodynamic molecular dispersion and adsorption kinetics controlling: model development and numerical simulation," Applied Water Science, vol. 7, no. 3, p. 1169-1189, 2017.

[12] C. M. Chang and V. S. Manoranjan, "Travelling wave solutions of a contaminant transport model with nonlinear sorption," Mathematical and Computer modelling, vol. 28, no. 9, pp. 1-10, 1998.

[13] P. Grindrod, The theory and applications of reaction-diffusion equations : patterns and waves, Oxford university press, 1996.

[14] G. Juan, M. Serguei, E.-P. Rafael, L.-G. Irvin and M. Moranchel, "Analytical solution to the diffusion, sorption and decay chain equation in a saturated porous medium between two reservoirs," Journal of Environmental Radioactivity, vol. 139, pp. 163-170, 2015. 
[15] M.W. Hirsch, S. Smale and R. L. Devaney, "Differential Equations, Dynamical Systems \& An Introduction to Chaos," elsevier academic press, second edition 2003.

[16] S.H. Strogatz, "NonLinear Dynamics and Chaos with Applications to Physics, Biology, Chemistry and Engineering," westviewpress, 2000.

[17] Y. Serwaa, A. Thomas and F. J. John, "Numerical modeling of radionuclide migration through a borehole disposal site," Earth and Environmental Sciences, vol. 3, no. 1, p. 155, 2014.

[18] T. A. Fashanu and V. O. S. Olunloyo, "A New Space-Time CE/SE Numerical Tracking of Contaminant Transport in Fractured Stratified Geologic Profiles," Computational Water, Energy, and Environmental Engineering, vol. 3, no. 1, pp. 8-21, 2014.
[19] C. R. M. Ana, S. B. Paulo, C. C. Murilo, C. R. M. Ana, D. Z. Edgar and A. P. Nivaldo, "Characterization and In Vivo Biological Performance of Biosilicat.," BioMed Research International, p. 7, 2013.

[20] R. A. Wuana , F. E. Okieimen, R. N. Vesuwe, "Mixed contaminant interactions in soil: Implocations, risk assesment and remediation," African Journal of Environmental Science and Technology, vol. 8(12), pp. 691-706, 2014.

[21] E. Shagalova , O. Zhukova, M. Germenchuk, I. Matveenko, Zh. Bakarikova "Dynamics of radiation situation on the territory of Belarus and migration of radionuclides in different types of soils after Chernobyl catastrophe," Journal of Radioanalytical and Nuclear Chemistry, vol. 246(3), pp. 521-525, 2000. 